\title{
동작관찰을 병행한 체감각 훈련이 뇌졸중 환자의 상지 근 활성도 및 손 기능에 미치는 영향
}

\author{
정중우 ${ }^{1}$, 한소영 ${ }^{2}$, 송보경*3 \\ ${ }^{1}$ 보바스기념병원 작업치료실, ${ }^{2}$ 보바스기념병원 작업치료실, ${ }^{*}$ 강원대학교 보건과학대학 작업치료학과
}

\author{
The Effects of Somatosensory Training Combined with Action Observation on the Upper \\ Limb of Muscle Activity and Hand Function in Stroke Patients \\ Jung-Woo Jeong ${ }^{1}$, So-young Han², Bo-kyoung Song ${ }^{* 3}$ \\ ${ }^{1}$ Dept. of Occupational Therapy, Bobath Memorial Hospital, Republic of Korea, \\ ${ }^{2}$ Dept. of Occupational Therapy, Bobath Memorial Hospital, Republic of Korea, \\ ${ }^{*}$ Dept. of Occupational Therapy, College of Health Welfare, Kangwon National University, Republic of Korea
}

Purpose The aim of this study was to investigate the effect of somatosensory training combined with action observation on the muscle activity of upper extremity and hand function in patients with stroke. Methods Twenty-two stroke patients who were hospitalized at B hospital in Gyeonggi - do during the period from September 2018 to March 2019 were enrolled in this study. The subjects were divided into 11 sensory training groups that intercepted action observation and intervention. The upper limb of muscle activity and hand function were evaluated before intervention, and intervention was performed 3 times a week, 40 minutes, 4 weeks, and the same evaluation was performed after intervention. Results As shown by the result of the muscle activity there was a statistically significant difference in anterior deltoid, triceps, and wrist extensor longus in the sensory training group with action observation, but there was no statistically significant difference in the somatosensory training group without action observation. As shown by the result of the hand function there was a statistically significant difference in somatosensory training with action observation which was performed the hand function before and after the intervention. There was no statistically significant difference somatosensory training without action observation. Conclusion This study demonstrated that somatosensory training combined with action observation significantly improves the function of patients with stroke.

Key words Stroke, Somatosensory Training, Action Observation, Muscle Actvitiy, Hand Function

Corresponding author Bo-Kyoung Song (bksong@kangwon.ac.kr)

Received date

Revised date

Accept date
01 October 2019

07 October 2019

20 October 2019

\section{I. 서론}

뇌졸중은 뇌혈관 장애로 인한 질환 및 사고를 모두 정의하며, 뇌졸중은 발병 후 $70 \%$ 이상의 편마비, 감각손상, 인지 및 시 지각장애, 삼킴 장애 등의 다양한 후유증을 유발하는 만성질 환으로 적극적인 관리가 필요하다 ${ }^{1)}$.

일반적인 뇌졸중 환자의 상지 기능의 회복은 하지에 비하 여 예후가 좋지 못한데, 이는 발병부위에 의한 것일 수도 있 지만, 상지가 하지에 비해 일상생활에서의 반복적인 운동의 기회가 적어 뇌의 재조직화의 기회가 적기 때문이다. ${ }^{3}$ 뇌졸중 환자들의 마비측 상지 기능 장애는 독립적 일상생활활동을 방

http:dx.doi.org/10.17817/2019.10.07.111460
해하는 가장 큰 원인으로 여겨지고 있다. ${ }^{4)}$ 이러한 상지기능 장애들은 일상생활활동의 독립적인 활동에 영향을 주게 되고, 그로 인해 옷입기, 식사하기, 개인의 활동과 같은 독립적인 일 상생활활동에 제한을 주게 되며, 타인의 의존성을 높임으로써 삶의 질을 저하시키는 원인이 된다. ${ }^{5}$ 상지의 기능 장애로 인 한 마비측의 장기간 비사용은 학습화되어 구체적인 과제수행 을 위한 기능의 저하를 초래할 수 있으며, 대운동기능 및 소 운동기능, 공동운동패턴(synergic movement pattern)등의 장애로 인해 상지의 일상생활활동 수행에 제한을 준다. ${ }^{6}$

팔의 뻗기와 집기 기능은 감각 수용기에서 전달된 감각정 보를 통해 수행되지만, 뇌졸중 환자의 $50 \%$ 에서 감각이 손상 되고, 특히 가벼운 촉각과 고유수용성감각 이 손상되면 물건 조작능력과 운동조절 능력을 저하시킨다. ${ }^{7)}$ 일반적으로, 좌측 
뇌병변 환자가 $25 \%$ 에서 그리고 우측 뇌병변 환자가 $37 \%$ 에서 감각 장애의 증상이 나타나는 것으로 보고되며, 가장 두드러 지게 나타나는 감각 결핍은 촉각 인식으로 그로 인해 물건을 조작하는 능력에 장애가 발생한다. ${ }^{8)}$ 이러한 감각 장애로 인해 뇌졸중 환자들은 일상생활활동에서 물체 조작, 상지의 기능적 활동수행 등의 다양한 장애를 초래한다.

뇌졸중 환자의 재활에서 중요한 목표 중 하나는 독립적인 일상생활활동을 제한하는 마비된 상지의 기능적 향상이다." 상지 기능 증진을 위해 효과적이고 새로운 치료를 탐색하고 연구하는 것은 무엇보다도 중요하다. ${ }^{10)}$ 대표적인 상지 기능 증진을 위한 치료법으로는 체감각 훈련, 동작관찰훈련, 과제 지향적 접근, 양측성 상지 훈련, 강제유도운동치료, 신경발달 치료, 상상훈련, 거울치료 등이 있다. ${ }^{11)}$

체감각 훈련이란 팔과 손의 피부에 위치하는 가벼운 접촉 감각 및 근육또는 관절에 위치하는 고유 감각정보를 통해 체 감각을 인지하며, 관절의 위치 및 근육의 신장 또는 수축을 인식함으로써 신체 위치 및 움직임을 조절할 수 있는 구심성 자극 정보와 훈련을 의미한다. ${ }^{12)}$ Winward 등(2007)의 연구 에서도 체감각의 이상을 가진 뇌졸중 환자를 대상으로 발병 1 개월 이내의 군과 발병 6개월 이내의 군으로 배정하여 체감각 의 회복을 관찰한 결과, 두 군에서 확연히 체감각의 회복은 보이지 않았지만 고유 감각에서 기능적인 회복을 보고하였 다. ${ }^{13)}$ Smania 등(2003)은 상지의 감각장애를 지닌 뇌졸중 환 자에게 체감각훈련을 통한 기능적 회복을 위한 다양한 중재 프로그램들 또한 피험자의 감각 회복에 많은 긍정적인 회복을 보고하였다. ${ }^{14)}$

동작관찰훈련이란 거울신경세포 시스템 이론에 근거한 새 로운 상지기능 회복의 치료 접근법으로써, 동작을 관찰하며 모방한 후 그 동작들을 지속적 혹은 반복적으로 훈련하는 방 법이다. ${ }^{15)}$ 동작관찰훈련은 다른 사람의 움직임 또는 동작을 관찰함으로써 형태와 행동을 이해하고 모방하는 것이라고 할 수 있다. ${ }^{16)}$ 거울신경세포는 마카크 원숭이를 통해 배쪽운동앞 겉질인 F5영역에서 처음 발견되었다. 이 영역은 사람에게 있 어 브로카 영역으로 사료된다. 마카크 원숭이의 F5영역은 목 표 지향적 동작에 대해서 운동영역의 투사가 이루어지는 곳이 다. 입 또는 손이 목표지향적활동의 동작을 실행하는 동안 F5 영역은 활성화되어 원숭이 또는 사람이 같은 움직임이나 비슷 한 동작을 관찰할 때 반응을 한다. ${ }^{17)}$ 거울신경세포 또한 목표 지향적인 활동에 의하여 활성화가 된다. 동작관찰은 관찰과 목표가 부합이 되는 과제를 모방함으로써 뇌졸중 환자의 상지 기능적 향상되었다고 하였다. ${ }^{18)}$ 이러한 동작관찰은 또한 일상 생활활동에 관련된 과제가 상지 기능에 유의미한 향상을 보고 하였다. ${ }^{19)}$

현재까지 연구로 볼 때에 동작관찰훈련과 체감각을 통한
상지 기능 증진의 사례는 오늘날까지 꾸준히 보고되어지고 있 다. 그러나 뇌 속에서 감각의 경로와 해석이 전혀 다른 두 가 지 감각이 뇌졸중 환자의 상지 기능에 미치는 영향에 대해 보 고된 연구는 이루어지지 않고 있다. 즉, 특수감각을 기반한 동 작관찰과 손과 상지의 체감각정보의 차이를 확인하기 위해 본 연구를 제시하고자 한다. 따라서 본 연구는 동작관찰을 병행 한 체감각 훈련이 뇌졸중 환자의 상지 근 활성도 및 손 기능 에 미치는 영향을 알아보고, 이러한 변화가 뇌졸중 환자의 상 지기능 회복에 있어 어떠한 영향을 주는지 알아본다.

\section{II. 연구 방법}

\section{1. 연구기간 및 대상}

본 연구는 경기도 성남에 위치한 B병원 재활의학과에 2019년 2 월부터 6 월까지 입원 중인 환자들 중에 사전검사를 통하여 연구 참여의 동의와 함께 22 명의 환자를 선정하였다. 각각의 중재 방법에 따라 동작관찰을 병행한 체감각 훈련군 11 명, 동 작관찰을 차단한 체감각 훈련군 11 명으로 무작위로 배정하여 진행하였다. 본 연구에서 정하는 대상자의 조건은 다음과 같다. (1) 재활의학과 전문의로부터 뇌졸중 편마비 진단을 받은 자

(2) 뇌졸중의 발병일이 3 개월에서 24 개월 사이로 다시 재발하 지 않은 자

(3) 마비측 손에 가벼운촉각 혹은 고유감각의 손상을 가지고 있는 자

(4) 버그균형척도를 통해 혼자서 앉아있기 혹은 서 있기가 가 능한 자

(5) 비운동성 시지각 검사(motor-free visual perception test, MVPT)를 통해 편측무시를 포함한 외과적 질환이나 시지각 장애를 가지고 있지 않은 자

(6) 한국판 몬트리올 인지평가(K-MoCA)가 23점 이상, 연구 자의 지시에 이해할 수 있는 자

(7) 본 연구의 내용을 이해하고 적극적으로 참여할 것을 동의 한 자

\section{2. 연구절차}

중재 전 필요한 검사를 실시한 후 동작관찰을 병행한 체감각 훈련군과 동작관찰을 차단한 체감각 훈련군에 블록 무작위 배 정(blocked randomization)을 통해 무작위로 배정하였다. 각 집단은 주 5 회 90 분간 물리치료, 주 5 회 60 분간 작업치료 를 실시하여 보존적 치료를 받았다. 본 연구를 위해 중재는 기존에 실시하고 있는 정규 치료 이외에 동작관찰을 병행한 체감각 훈련군은 4 주간 주 3 회, 1 회 40 분, 동작관찰을 차단한 체감각 훈련군 또한 4 주간 주 3 회, 1 회 40 분씩 실시하였다. 또 
한 연구 목적과 중재에 대해 이해하고 경력 3 년차 이상의 작 업치료사들에 의해 연구를 진행하였다. 각 집단은 중재 전 사 전 평가를 시행하였으며, 중재 후 사후 평가를 진행하였다.

\section{3. 중재방법}

(1) 동작관찰을 병행한 체감각 훈련군

본 연구에서 연구군에 적용할 체감각 훈련은 Champion (2009)이 연구한 내용을 수정 보완하여 실시하였다. 어깨와 위팔 부위의 치료는 바로 앉은 자세에서 어깨 복합체의 동작 을 촉진한다. 치료사는 어깨뼈와 몸통의 분절적인 움직임을 위해 점차 안정가동성(mobile stability)을 증가시킨다. 이후 몸통의 움직임을 제한하면서 어깨뼈와 위팔뼈의 관절움직임을 이용하여 어깨띠둘레근과 어깨세모근, 위팔세갈래근, 위팔두갈 래근 등의 어깨 주위 근육의 고유감각을 자극한다. 그리고 손 과 어깨 복합체가 함께 움직이는 과정과 손의 쥐기 기능을 이 용하여 손 뻔기 등의 기능적 활동과 연결하도록 한다. 이후 마비측 아래팔 부위와 손이 바닥에 잘 접촉하도록 한 후 굽힘 이 나타나지 않도록 손가락의 적절한 길이를 확보되도록 한 다. 그리고 엄지손가락을 자극하여 고정한 후 2 번째부터 5 번 째 손가락의 길이를 조정하여 손가락의 굽힘이 일어나지 않도 록 외재근의 길이를 확보한다. 다시 내재근의 길이를 조절하 여 두 근육군의 고유 감각을 자극하고 점진적으로 손가락과 손 전체의 움직임을 증진시킨다(Figure 1). ${ }^{20)}$

동작관찰훈련은Franceschini 등(2010)이 고안한 치료프 로그램을 수정보완하여4가지의 물 마시기, 전화받기, 책상닦

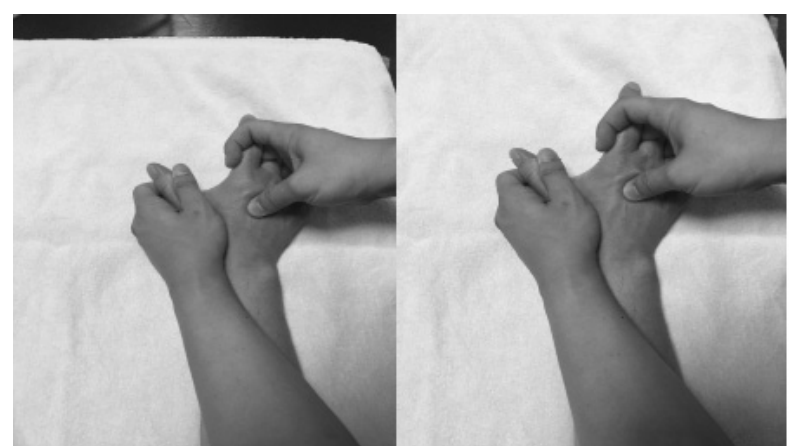

Figure1. Somatosensory training

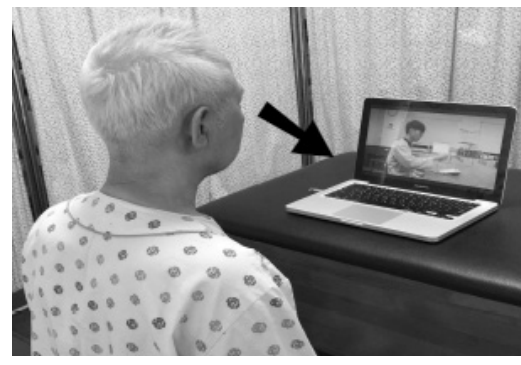

Figure2. Action observation training
기, 책장 넘기기로 과제를 선정하였다. 동영상은 측면, 뒷면, 윗면에서 각각 $45^{\circ}$ 방향으로 촬영하였다. 동영상은 일반 속도, 0.5 배 느린속도, 그리고 일반속도의 순으로 하며, 과제당 $4 \sim 5$ 분정도로 편집하였다. 대상자는 조용하고, 독립된 치료실에서 13 inch 노트북를 통해 4가지 과제 중 회기당 2가지씩 과제 를 관찰한 후 모방활동을 수행하였다(Figure 2). ${ }^{19)}$ 본 연구의 연구군은 체감각훈련을 20 분간 실시한 후 동작관찰훈련을 10 분간 관찰한 후 모방훈련을 10 분간 실시하였다.

\section{(2) 동작관찰을 차단한 체감각 훈련군}

본 연구의 대조군은 체감각 훈련을 20 분간 실시하였으며 이후 동작관찰 없이 모방훈련을 20 분간 진행하였다.

\section{4. 측정도구}

(1) 표면근전도(electromyograph; EMG) 검사

근육의 근전도 신호를 측정하기 위하여 신경과 근섬유에서 나 오는 복합 활동전위(compound action potential)를 기록하 는데 좋고 사용이 용이한 표면근전도를 사용하였다. 사용된 표면근전도는 Input Impedance가 $10 \sim 12 \mathrm{ohm}, 20 \mathrm{~Hz}$ 에서 Common Mode Rejection Ratio(CMRR)가 90dB인 QEMG-4(LXM3204, LAXTHA, Korea)를 사용하여 근전도 신호를 수집하였다. 본 연구에서 근전도 기준 수축 값은 의자 에 앉은 자세에서 빈 물병을 잡은 상태에로 $30 \mathrm{~cm}$ 앞 테이블 위에 올려 놓는 자세로 수집하였다. 측정 절차에 따른 각 근 육별 부착 부위는 앞어깨세모근, 위팔두갈래근, 위팔세갈래근, 긴노쪽손목폄근으로 하였으며 근섬유방향과 되도록 평행하도 록 근복에 부착하였다(Figure 3). ${ }^{21)}$

본 연구에서 근전도 기준 수축 값은 의자에 앉은 자세에서 빈 물병을 잡은 상태에로 $30 \mathrm{~cm}$ 앞 테이블 위에 올려 놓는 자 세로 수집하였다. 수집된 근전도 아날로그 신호는 QEMG-4 시스템으로 보내져 디지털 신호로 바뀐 다음, 개인용 컴퓨터 에서 TeleScan ver.3.15 를 이용하여 필터링과 기타 신호처 리를 하였다. 근전도 신호에서의 표본 추출률은 $256 \mathrm{~Hz}$ 로 설 정하였다. 첫번째로 $\% \mathrm{RVC}$ 값 통해 정규화하였으며 RMS 값을

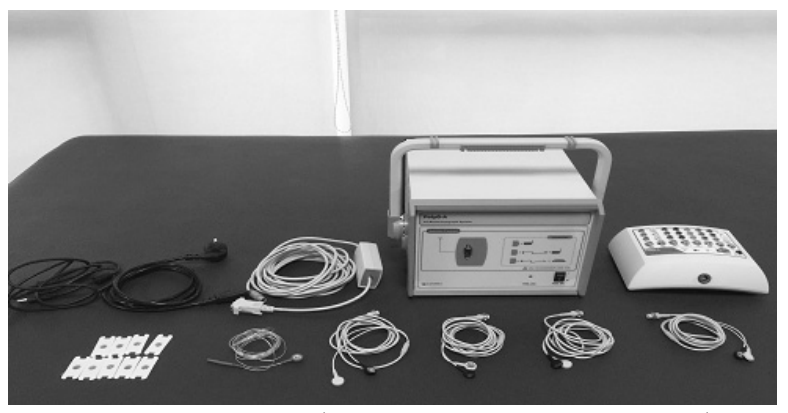

Figure3. QEMG-4(LXM3204, LAXTHA, Korea) 


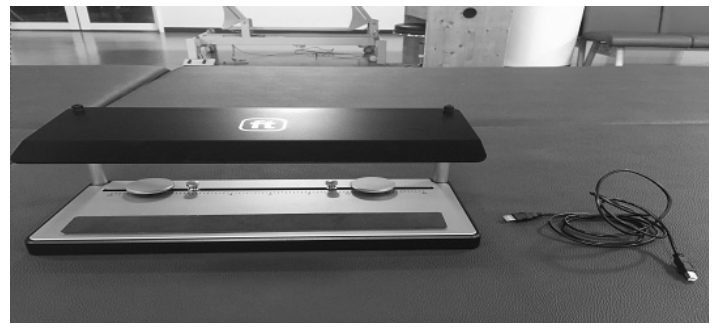

Figure 4. Finger Touch System

구하여 이를 동작단위로 윈도우를 설정하였다. 오버랩 비율은 $90 \%$ 로 설정하여 구하였다.

(2) 손 기능 검사

본 연구는 손가락 힘을 측정하기 위해 Finger Touch (FT; precision $=0.196 \mathrm{~N}$, sampling rate $=30 \sim 32 \mathrm{~Hz}$; SeedTech Co., South Korea) 시스템을 사용하였다. 피검사 자는 힘 측정 센서 및 스크린으로부터 각각 $50,70 \mathrm{~cm}$ 거리에 착석하고, finger dynamometers는 중앙을 기준으로 좌, 우 $15 \mathrm{~cm}$ 떨어진 위치에 고정된다. FT 시스템은 손가락 힘 측정 을 위한 두 개의 finger dynamometer와 힘 측정 정보 제공 용 스크린으로 구성된다(Figure 4). 본 검사에서는 3회기 측 정의 평균치를 기준으로 점수화 하였다.

\section{5. 분석방법}

본 연구에서 수집된 자료의 통계처리는 window SPSS version 18.0 을 이용하여 분석하였다. 연구 대상자의 일반적 특 성은 기술통계를 사용하여 평균과 표준편차를 분석하였으며, 카이제곱 검정을 통해 두 집단간 동질성 검증 및 정규성 검정 을 진행하였다. 연구군 및 대조군의 그룹 내 중재 전후 상지 근 활성도와 손 기능의 변화를 알아보기 위해 대응표본 t-검정 (Paired t-test)을 사용하였으며, 두 그룹간 차이를 알아보기 위해 독립표본 t-검정(Independent t-test)를 실시하였다.. 본 연구의 모든 통계적 유의수준은 $\alpha=0.05$ 로 진행하였다.

\section{III. 결 과}

\section{1. 대상자의 일반적 특성}

본 연구에 참여한 전체 대상자는 총 22 명으로 동작관찰을 병 행한 체감각훈련군 11 명과 동작관찰을 차단한 체감각훈련군 11 명으로 무작위 배정 되었으며, 두 그룹간의 성멸, 연령, 발 병유형, 손상부위, 발병기간의 따른 유의미한 차이는 없었다 ( $p>$.05). 본 연구에 참여한 대상자의 자세한 정보는 다음과 같다(Table 1).

Table 1. General characteristics of the subjects

\begin{tabular}{|c|c|c|c|c|c|}
\hline Characteristics & Division & Experimental group & Control group & $x^{2} / t$ & p \\
\hline \multirow{2}{*}{ Gender(person) } & Male & $5(45.5 \%)$ & $5(45.5 \%)$ & \multirow{2}{*}{.6} & \multirow{2}{*}{.74} \\
\hline & Female & $6(54.5 \%)$ & $6(54.5 \%)$ & & \\
\hline \multirow{2}{*}{ Type of Paralysis } & Left & $5(45.5 \%)$ & $5(45.5 \%)$ & \multirow{2}{*}{.17} & \multirow{2}{*}{.12} \\
\hline & Right & $6(54.5 \%)$ & $6(54.5 \%)$ & & \\
\hline \multirow{2}{*}{ Type of brain damage } & Hemorrage & $6(54.5 \%)$ & $6(54.5 \%)$ & \multirow{2}{*}{.6} & \multirow{2}{*}{.74} \\
\hline & Infarction & $5(45.5 \%)$ & $5(45.5 \%)$ & & \\
\hline \multirow{3}{*}{ Duration of diseade(month) } & Less than 6 months & $3(27.3 \%)$ & $3(27.3 \%)$ & \multirow{3}{*}{. } & \multirow{3}{*}{1} \\
\hline & 6 12 months & $5(45.5 \%)$ & $5(45.5 \%)$ & & \\
\hline & 12 24months & $3(27.3 \%)$ & $3(27.3 \%)$ & & \\
\hline $\mathrm{K}-\mathrm{MoCA}$, mean $\pm \mathrm{SD}$ & & $25.64 \pm 2.33$ & $25.91 \pm 2.16$ & .28 & .77 \\
\hline \multirow{6}{*}{ Averge age(age) } & $10 \mathrm{~s}$ & $1(9.1 \%)$ & $1(9.1 \%)$ & \multirow{6}{*}{.15} & \multirow{6}{*}{.88} \\
\hline & $20 \mathrm{~s}$ & $1(9.1 \%)$ & $2(18.2 \%)$ & & \\
\hline & $30 \mathrm{~s}$ & $3(27.3 \%)$ & $1(9.1 \%)$ & & \\
\hline & $40 \mathrm{~s}$ & $3(27.3 \%)$ & $4(36.4 \%)$ & & \\
\hline & $50 \mathrm{~s}$ & $2(18.2 \%)$ & $3(27.3 \%)$ & & \\
\hline & $60 \mathrm{~s}$ & $1(9.1 \%)$ & $0(0 \%)$ & & \\
\hline
\end{tabular}

The values are mean (standard deviation) 


\section{2. 집단 내 중재 전, 후 상지 근활성도 및 손 기능 비교}

연구군의 중재 전·후 근 활성도 중 앞어깨세모근, 위팔세갈래 근, 긴노쪽손목폄근의 변화를 비교한 결과 통계적으로 유의미 한 차이를 보였다(* $\mathrm{p}<.05)$. 위팔두갈래근의 변화를 비교한 결 과 통계적으로 유의미한 차이는 보이지 않았다( $p>$.05). 대조 군의 중재 전·후 근 활성도 결과 앞어깨세모근, 위팔두갈래근, 위팔세갈래근, 긴노쪽손목폄근 모두 향상되었으나 통계적으로 유의미한 차이는 보이지 않았다( $p>$.05).

연구군의 중재 전·후 손 기능 변화를 비교한 결과 통계적 으로 유의미한 차이를 보였다(*p<.05). 대조군의 중재 전·후 손 기능 변화를 비교한 결과 향상되었으나 통계적으로 유의미 한 차이는 보이지 않았다(p>.05)(Table 2).

\section{3. 집단 간 중재 전, 후 상지 근 활성도 및 손 기능 변화 비교} 중재 후 연구군과 대조군의 근 활성도 변화 중 앞어깨세모근, 위팔두갈래근, 위팔세갈래근, 긴노쪽손목폄근은 통계적으로 유 의미한 차이를 보이지 않았다(p>.05). 중재 후 연구군과 대조 군의 손 기능 검사에서 통계적으로 유의미한 차이를 보이지 않았다(p>.05)(Table 2).

\section{IV. 고 찰}

본 연구는 뇌졸중 환자를 대상으로 동작관찰을 병행한 체감각 훈련이 대상자의 상지 근 활성도 및 손 기능에 어떠한 영향을 미치는지 알아보고자 하였다. 본 연구는 경기도 성남에 위치 한 $\mathrm{B}$ 병원 재활의학과에 입원 중인 환자들 중에 사전검사를 통하여 연구 참여의 동의와 함께 22 명의 환자를 선정하였다. 각각의 중재 방법에 따라 동작관찰을 병행한 체감각 훈련군 11 명, 동작관찰을 차단한 체감각 훈련군 11 명으로 무작위로 배정하여 진행하였다.
뇌졸중 후 상지기능의 제한은 매우 흔한 증상으로, 일반적 으로 뇌졸중 환자의 $85 \%$ 가 초기에 상지 기능의 장애를 나타 내며, 이후 환자의 55 75\%에서 장애가 지속적으로 나타나 일상생활활동을 수행할 때 기능을 제한하는 원인이 된다. ${ }^{22}$ 따라서 개인의 독립성 회복을 통해 일상생활에서의 복귀를 최 우선으로 하는 작업치료사에게 마비측 상지 기능의 회복은 중 요한 치료 목표가 되어지고 있다. ${ }^{23)}$

본 연구의 결과 동작관찰을 병행한 체감각 훈련의 연구군 은 상지 근 활성도 검사 중 앞어깨세모근, 위팔세갈래근, 긴노 쪽손목폄근, 손 기능에서 유의미한 향상이 있었음을 알 수 있 었다. 그러나 위팔두갈래근에서는 유의미한 향상을 보이지 않 았다. 또한 대조군에서도 상지 근 활성도검사와 손 기능에서 유의미한 향상을 보이지 않았다. Smania 등(2003)이 시행한 연구에서는 상지 체감각 훈련과 그에 따른 인식에 관한 몇 가 지의 중재를 제공한 후 그 결과 모든 대상자들이 감각에서의 증진을 보이고 마비측 상지의 기능적 사용이 증가함을 보고 하였다. ${ }^{14)}$ 방대혁 등(2011)은 만성 뇌졸중 환자를 대상으로 동작관찰훈련이 과제 집중 훈련 그룹보다 더 상지기능을 유의 하게 향상하였다고 보고하였다. ${ }^{24}$ 이러한 선행연구를 비추어 보았을 때 피부의 기계적 수용기를 통한 체감각 훈련과 시각 적 보상을 통한 동작관찰 훈련이 상지 움직임을 더욱 개선하 고 기능적 향상을 제공하는 것으로 사료된다. 그러나 위팔두 갈래근에서 향상이 나타나지 않았던 것은 물체를 향해 손을 뻗을 때 활용되는 앞어깨세모근, 위팔세갈래근과 같은 주동근 의 향상에 따른 대항근인 위팔두갈래근의 근수축 감소 원인으 로 생각된다. 이와 더불어 Gjelsvik 등(2008)은 과제의 성공 적인 완료를 가능하게 하기 위해서 감각의 입력과 함께 과제 지향적인 근육활동의 패턴이 이용되어진다고 강조하였다. ${ }^{25}$ 이러한 손을 뻗어 물체는 잡는 패턴이 상지 기능의 회복을 촉 진시킬 것이라 여겨진다.

본 연구의 연구군과 대조군의 집단 간 비교에서는 통계저

Table 2. Comparison of Results between Experimental group and control group

(unit :\%RVC)

\begin{tabular}{|c|c|c|c|c|c|c|c|}
\hline & \multicolumn{3}{|c|}{ Experimental group } & \multicolumn{3}{|c|}{ Control group } & \multirow{2}{*}{$\begin{array}{l}\text { Between groups } \\
\text { p-value }\end{array}$} \\
\hline & $\begin{array}{l}\text { Before } \\
\text { treatment }\end{array}$ & $\begin{array}{c}\text { After } \\
\text { treatment }\end{array}$ & $\mathrm{p}$-value & $\begin{array}{l}\text { Before } \\
\text { treatment }\end{array}$ & $\begin{array}{c}\text { After } \\
\text { treatment }\end{array}$ & $\mathrm{p}$-value & \\
\hline Anterior deltoid & $61.06 \pm 49.71$ & $69.13 \pm 53.17$ & $.01^{*}$ & $51.05 \pm 26.44$ & $50.69 \pm 28.30$ & .84 & .32 \\
\hline Biceps brachii & $34.25 \pm 12.29$ & $36.07 \pm 12.45$ & .15 & $40.14 \pm 18.28$ & $40.81 \pm 19.6$ & .37 & .51 \\
\hline Triceps brachii & $31.26 \pm 10.8$ & $34.84 \pm 12.75$ & $.02^{*}$ & $31.24 \pm 20.18$ & $30.32 \pm 20.77$ & .26 & .55 \\
\hline $\begin{array}{l}\text { Extensor carpi } \\
\text { radialis longus }\end{array}$ & $23.64 \pm 7.21$ & $24.75 \pm 6.4$ & $.04^{*}$ & $28.94 \pm 14.62$ & $26.7 \pm 9.73$ & .32 & .58 \\
\hline Finger touch & $2.05 \pm 1.18$ & $2.21 \pm 1.23$ & $.01^{*}$ & $2.82 \pm 1.03$ & $2.66 \pm 0.91$ & .21 & .33 \\
\hline
\end{tabular}

The values are mean \pm standard deviation, ${ }^{*} p<0.05$ by Paired $t$ test 
긍로 유의미한 차이를 보이지 않았다. 이러한 결과는 대조군 에서도 실시한 체감각 훈련 역시 상지 근 활성도와 손 기능에 서 긍정적인 영향을 주었음을 뒷받침하는 결과이다. 연구군과 대조군의 두 집단간 중재 후 변화량 차이에서 살펴보면 연구 군에서 유의미한 변화량을 확인하였다. 이는 단순한 시각적 자극을 통해 움직임의 보상이 주어지는 것이 아닌 체감각을 통해 직접적 자극과 시각을 통한 간접적 자극이 병행되어 짐 으로써 움직임에 대한 인식이 명료화 되었을 것이라 사료된 다. 뇌졸중 환자의 상지기능 회복은 목표지향적인 활동을 통 해 많이 이루어진다. ${ }^{25)}$ 또한 동작관찰에 이용한 과제 역시 일 상생활활동에 익숙한 과제를 선정함으로써 상지 기능 향상에 도움이 되었을 것이라 판단되며 더불어 대상자가 원하고 동기 부여를 통한 과제 선정이 중요할 것이라 사료된다.

본 연구의 제한점은 대상자의 수가 적어 연구결과에 따른 일반화의 제한이 있으며, 4 주라는 연구기간이 중재의 효과성 을 증명하기에는 어려움이 있었으며 또한 선정 기준에 부합하 는 대상자 모집이 어려워 적은 대상자 수가 적었다. 또한 두 훈련군 모두 실험 이외의 운동치료를 비롯한 그외 시간에 상 지 및 손과 관련된 훈련을 진행하지 않도록 제제하였으나 모 든 환경을 통제하기 힘들었다는 점이 있었다. 추후 연구에서 는 근 활성도, 손 기능에 대한 항목을 구체적으로 세분화하여 동작관찰과 체감각 훈련이 상지 기능 회복에 미치는 효과성을 입증하는 연구가 필요할 것으로 사료된다. 그리고 현재의 대 상자를 기반으로 추후 추적 관찰하며, 더 많은 대상자를 통해 체감각 훈련과 동작관찰 훈련의 효과를 입증하는 연구 또한 필요할 것으로 사료된다. 또한 본 연구의 결과가 동작관찰 훈 련과 체감각 훈련을 통해 뇌졸중 환자의 상지 기능적 회복을 위한 임상적 자료로 활용되어지길 기대한다.

\section{Reference}

1. Arsic S, Eminovic F, Konstantinovic L, et al. Correlation between functional independence and quality of executive functions in stroke patients. Turk J Phys Med Rehab. 2015;61:333-8.

2. Gowland C, Bruin de H, Basmajian V J, et al. Agonist and antagonist activity during voluntary upper limb movement in patients with stroke. Phys Ther. 1992;72(9):624-33.

3. Shumway-Cook A, Woollacott MH. Motor control (3rd ed). Lippincott Williams \& Wilkins; 2002.

4. De Kroon JR, IJzerman MJ, Lankhorst GJ, et al. Electrical stimulation of the upper limb in stroke: Stimulation of the extensors of the hand vs. alternate stimulation of flexors and extensors. Am J Phys Med Rehabil.
2004;83(8):592-600.

5. Kim HS, Hwang YO, Yu JH, et al. The Correlation Between Depression, Motivation for Rehabilitation, Activities of Daily Living, and Quality of Life in Stroke Patients. Journal of Korean Society of Occupational Therapy. 2009;17(3):41-53.

6. Jorgensen HS, Nakayama $\mathrm{H}$, Raaschou $\mathrm{HO}$, et al. Outcome and time course of recovery in stroke. Part II: Time course of recovery. The Copenhagen Stroke Study. Arch Phys Med Rehabil. 1995;76(5):406-12.

7. Trombly CA, Radomski MV, Trombly CA, et al. Occupational therapy for physical dysfunction. 2002.

8. Sterzi R, Bottini G, Celani M, et al. Hemianopia, hemianesthesia and hemiplegia after right and left hemisphere damage. a hemispheric difference. J Neurol Neurosurg Psychiatry. 1993;56(3):308-10.

9. Tavernese E, Paoloni M, Mangone M, et al. Segmental muscle vibration improves reaching movement in patients with chronic stroke:A randomized controlled trial. NeuroRehabilitation. 2013;32(3):591-9.

10. Susy M, Brawun MS, Anna J, et al. The effects of mental practice in stroke rehabilitation: A system review. Arch Phys Med Rehabil. 2006;87(6):842-52.

11. Oujamaa L, Relave I, Froger J, et al. Rehabilitation of arm function after stroke. Literature review. Ann Phys Rehabil Med. 2009;52(3):269-93.

12. Lundy-Ekman L. Neuroscience: Fundamentals for Rehabilitation. St. Louis, Mo: Saunders/Elsevier, 2007.

13. Winward CE,Halligan PW, Wade DT. Somatosensory recovery: a longitudinal study of the first6 months after unilateral stroke. Disabil Rehabil. 2007;29(4):293-9.

14. Smania N, Montagnana B, Faccioli S, et al. Rehabilitation of somaticsensation and related deficit of motor control in patients with pure sensory stroke. Arch Phys Med Rehabil. 2003;84:1692-702.

15. Sqandurra G, Ferrari A, Cossu G, et al. Upper Limb Children Action-observation Training (UP-CAT): A randomised controlled trial in hemiplegic. BMC Neurol. 2011;28;11:80.

16. Kim, K. M. Action observation for upper limb function after stroke: evidence-based review of randomized controlled trials. J Phys Ther Sci. 2015;27(10):3315-17.

17. Rizzolatti,G., Fadige,L., Gallese,V. et al. Premotor cortex and the recognition of motor actions. Brain Res Cogn Brain Res. 1996;3(2):131-41. 
18. Celink P, Webster B, Classer DM, et al. Effects of action observation on physical training after stroke. Stroke. 2008;39(6):1814-20.

19. Franceschini M, Agosti M, Cantagallo A, et al. Mirror neurons: action observation treatment as a tool in stroke rehabilitation. Eur J Phys Rehabil Med. 2010;46(4): 517-23.

20. Champion J, Barber C, Lynch-Ellerington M. Bobath concept. Theory and clinical practice in neurological rehabilitation: chapter7, Recovery of upper limb function. Wiley-Blackwell, Oxford, UnitedKingdom. 2009;18(5), 538-49.

21. Cram JR, Kasman GS, and Holtz J. Introduction to surface electromyography.Int J Psychosom. 1993;40(1-4):47-55.

22. Yavuzer G, Selles R, Sezer N, et al. Mirror Therapy Improves Hand Function in Subacute Stroke: A Randomized Controlled Trial. Arch Phys Med Rehabil.
2008;89(3):393-8.

23. Petruseviciene D, Krisciūnas A. Evaluation of activity and effectiveness of occupational therapy in stroke patients at the early stage of rehabilitation. Medicina (Kaunas). 2008;44(3):216-24.

24. Bang DH, Kang TW, Oh DW. Comparison of the effect of Action Observational training and Task-oriented training on Upper Limb Function and activities of daily living in People with Chronic stroke. Journal of Digital Convergence. 2012;10(9):409-16.

25. Gjelsvik BE. The bobath concept in adult neurology. Stuttgart,Germany. 2008.

26. Lin KC, Chung HY, Wu CY, et al. Constraint-induced therapy versus control intervention in patients with stroke: a functional magnetic resonance imaging study. Am J Phy Med Rehabil. 2010;89(3):177-85. 
